\begin{tabular}{c}
\hline TÜRK \\
TARIM ve DOĞA BiLIMLERI \\
DERGISI \\
\hline \hline
\end{tabular}

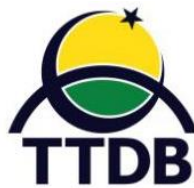



www.dergipark.gov.tr/turkjans

Araştırma Makalesi

\title{
Yemeklik Sakız Fasulyesinde Bitkide Tane Verimi Yönünden Genotip x Çevre İnteraksiyonunun Farklı Yöntemler ile İncelenmesi
}

\author{
Mevlüt AKÇURA ${ }^{1 *}$, Ahmet TURAN ${ }^{2}$ \\ ${ }^{1}$ Çanakkale Onsekiz Mart Üniversitesi, Ziraat Fakültesi, Tarla Bitkileri Bölümü, Çanakkale \\ ${ }^{2}$ Çanakkale Onsekiz Mart Üniversitesi, Fen Bilimleri Enstitüsü, Tarla Bitkileri Anabilim Dalı, Çanakkale \\ *Sorumlu Yazar: makcura@comu.edu.tr
}

Geliş Tarihi: 17.05.2020 Düzeltme Geliş Tarihi: 01.06.2020 Kabul Tarihi: 02.06.2020

\section{$\overline{0 ̈ z}$}

$\mathrm{Bu}$ araştırma altı farklı çevrede yetiştirilen sebze tipi sakız fasulyesi (Cyamopsis tetragonolaba) genotiplerinin bitki tane verimi yönünden stabilitelerini belirlemek amacıyla yürütülmüştür. Araştırmada 12 adet genotip kullanılmıştır. Denemeler tesadüf blokları deneme desenine göre üç tekerrürlü olarak kurulmuştur. Genotiplerin bitki tane verimi yönünden stabilitelerini belirlemek amacıyla $S^{(1)}, S^{(2)}, S^{(3)}, S^{(6)}, N P^{(1)}$, $N P^{(2)}, N P^{(3)}, N P^{(4)}, W_{i}{ }^{2}, \sigma_{i}^{2}, s^{2} d_{i}, b_{i}, C V i, \theta_{(i)}, \theta_{i}, K R$ parametreleri kullanılmıştır. Ayrıca, kullanılan yöntemler arasındaki ilişkileri görsel olarak değerlendirmek için heatmap ve biplot oluşturulmuştur. Sonuç olarak Samen çeşidi ile SF10 ve SF2 genotiplerinin kullanılan yöntemlerinin çoğunluğuna göre en stabil olduğu, yöntemlerin aralarındaki ilişkiye göre de dört grup oluşturduğu tespit edilmiştir. Birinci grubu bitki tane verimi ile $b_{i}$ ve $C V i$ oluşturmuştur. Bu grup ile olumlu ve önemli ilişkiye sahip olan ikinci grupta ise $s^{2} d_{i}, \sigma_{i}^{2}, \theta_{i}$, ve $W_{i}{ }^{2}$ yöntemleri yer almışır. Tane verimi ile olumsuz ve önemli ilişkiye sahip olan ve tamamı parametrik olmayan yöntemlerden oluşan dördüncü grubu ise $S^{(6)}, N P^{(2)}, N P^{(3)}, N P^{(4)}$ ve $K R$ yöntemleri oluşturmuştur. Sebze tipi sakız fasulyesinde bitki tane verimi yönünden stabil genotipleri belirlemek için çok sayıda yöntem kullanmak yerine her yöntem grubundan bir adet paremetrenin kullanılması yeterli yeterli olacağı ön görülmektedir.

Anahtar kelimeler: Cyamopsis tetragonolaba, sebze tipi sakız fasulyesi, bitkide tane verimi, stabilite

\section{Investigation of Genotype x Environment Interaction with Different Methods in Grain Yield of Edible Cluster Bean}

\begin{abstract}
This research was carried out to determine the stability of vegetable type cluster bean (Cyamopsis tetragonolaba) genotypes grown in different six environments in terms of plant grain yield. 12 genotypes were used in the study. Experiments were conducted randomized completed blocks design with replications. Among stability parameters such as $\mathrm{S}^{(1)}, \mathrm{S}^{(2)}, \mathrm{S}^{(3)}, \mathrm{S}^{(6)}, N \mathrm{P}^{(1)}, N \mathrm{P}^{(2)}, N \mathrm{P}^{(3)}, N \mathrm{P}^{(4)}, \mathrm{W}_{\mathrm{i}}{ }^{2}, \sigma^{2}{ }_{\mathrm{i}}, \mathrm{s}^{2} \mathrm{~d}_{\mathrm{i}}, \mathrm{b}_{\mathrm{i}}, C V \mathrm{i}, \theta_{(\mathrm{i})}, \theta_{\mathrm{i}}$ and $K R$ were used to determine the stability of genotypes in terms of plant seed yield. Besides, heatmap and biplots were created to evaluate the relationships between the methods used visually. As a result, it was determined that Samen variety and SF10 and SF2 genotypes were the most stable according to the majority of the methods used, and the methods formed four groups according to the relationship between them. The first group formed $b_{i}, C V i$, and plant seed yield. The second group, which has a positive and important relationship with the first group, includes the $s^{2} d_{i}, \sigma^{2}{ }_{i}, \theta_{i}$, and $W_{i}{ }^{2}$ parameters. Five non-parametric $\left(S^{(6)}, N P^{(2)}, N P^{(3)}, N P^{(4)}\right.$, and $\left.K R\right)$ methods consisted of the fourth group, which has a negative and important relationship with grain yield. . Instead of using a large number of methods to determine stable genotypes in terms of plant grain yield in vegetable type cluster bean, it will be sufficient to use one parameter from each method group.
\end{abstract}

Key words: Cyamopsis tetragonolaba, edible cluster bean, stability, plant seed yield. 


\section{Giriş}

Bitki ıslahının en önemli aşamalarından birisi başta tane verimi olmak üzere pek çok kantitatif özellik yönünden geliştirilen genotiplerin farklı çevrelere adaptasyonlarının belirlenmesidir (Sozen ve Karadavut, 2019). Bu amaçla ıslahçılar çoğu zaman farklı çevrelerde, bazı durumlarda ise tek çevrede sulama ve gübreleme ile oluşturdukları farklı ortamlarda denemeler yürütmektedirler. Farklı çevrelerde kurulan denemelerde ortaya çıkan genotip çevre interaksiyonu (GÇi) nun istatistik analizi için tek değişkenli (parametrik veya parametrik olmayan) ve çok değişkenli farklı stabilite analiz yöntemleri geliştirilmiştir (Flores ve ark., 1998; Sozen ve Karadvut, 2018). Tek değişkenli stabilite analizlerinde Gçi'yi yorumlamak için iki ana istatistiksel grup vardır. Birinci grup parametrik yöntemlerden oluşur. Parametrik analizler regresyon katsayısı ( $b_{i}$; Finlay ve Wilkinson, 1963), regresyondan sapma varyansı (Sdi ${ }^{2}$; Eberhart ve Russell, 1966), Wricke'nin ekovalans kararlılık indeksi ( $\mathrm{Wi}^{2}$; Wricke, 1962), Shukla'nın stabilite varyansı $\left(\sigma_{i}^{2}\right.$; Shukla, 1972), çevresel değişim katsayısı $\left(\mathrm{CV}_{\mathrm{i}}\right.$; Francis ve Kannenberg, 1978), ortalama varyans ( $\theta_{i}$; Plaisted ve Peterson, 1959), GE varyans bileşeni $\left(\theta_{(\mathrm{i})}\right.$; Plaisted, 1960) ve verim stabilitesi indeksi (YS ; Kang, 1988) yöntemlerinden oluşur. Parametrik istatistikler ekonomik öneme sahip kantitatif özelliklerin değerlendirilmesinde yaygın olarak kullanılmaktadır (Akçura ve ark., 2006; Sozen ve ark., 2018). Parametrik istatistiklerin etkin olabilmesi için verilerin normal dağılıma uyması, varyansın homojen olması Gçi'nin birleştirilmiş varyans analizinde istatistiksel olarak önemli olması gerekmektedir.

Tek değişkenli kararlılık analizlerinde ikinci grup ise parametrik olmayan yöntemlerdir (Akçura ve Kaya, 2008). Bu gruptaki yöntemlerde parametrik yöntemlerde olduğu gibi GÇí'nin önemli, varyansların homojen ve verilerin normal dağılıma uygun olması zorunluluğu yoktur (Huhn, 1990). Parametrik olmayan stabilite analizleri, Nassar ve Huhn'un istatistikleri (S ${ }^{(1)}, \mathrm{S}^{(2)}$; Nassar ve Huhn, 1987), Huhn'in istatistikleri ( $S^{(3)}$ ve $S^{(6)}$; Huhn, 1990), Thennarasu'nun istatistikleri (NP(i); Thennarasu, 1995), Kang'ın sıra toplamı (KR; Kang, 1988) ve Fox'un en üst sıra (en üst sıra; Fox ve ark., 1990) yöntemlerinden oluşmaktadır. Sıralı verilerden hesaplanan parametrik olmayan istatistikler, parametrik istatistiklere alternatiftir (Nassar ve Huhn, 1987). Bundan dolayı dayanıklılık ıslahı çalışmaları başta olmak üzere farklı çalışmalarda kolaylıkla kullanılabilir (Hocaoğlu ve ark., 2020). Parametrik ve parametrik olmayan stabilite yöntemlerinin stabil genotipleri belirlemede incelenen kantitatif özelliğe bağlı olarak güçlü ve zayıf yönleri vardır. Bu nedenle bitki ıslahçıları çoğu zaman hem parametrik hemde parametrik olmayan stabilite yöntemlerini aynı anda kullanmaktadırlar (Becker ve Leon, 1988; Sozen ve ark., 2017). Stabilite analiz yöntemlerinin kullanılabilirliği araştırıcıların analiz yaptıkları istatistik programlarına erişimine bağlı olarak da değişebilmektedir. Bu çalışmada, PourAboughadareh ve ark., (2019) tarafından R programı tabanlı geliştirilen ve online olarak farklı stabilite istatistiklerini hesaplayan STABILITYSOFT programı kullanılmıştır (https://manzik.com/stabilitysoft/).

Sakız fasulyesi [Cyamopsis tetragonoloba (L.) Taub.] [2n = 14] uluslararası literatürde guar ve küme fasulyesi (cluster bean) olarak bilinir. Tarımı yapılan bitkiler arasında oldukça farklı sektörlerde (petrol sanayisinden gıda sanayisine kadar) kullanılan sayılı bitkilerdendir. Sakız fasulyesi, temelde tohumunda \%30-35 oranında bulunan sakız için yetiştirilen bir bitki-olmasına rağmen sebze amaçlı kullanılan tipleride vardır (Girish ve ark., 2012). Sebze olarak kullanılan tiplerin meyveleri uzun ve taneleri iridir. Araştırmada Türkiye de geliştirilmiş olan sebze tipi sakız fasulyesi genotipleri kullanılmıştır.

Çalışma, farklı çevrelerde yetiştirilen sebze tipi sakız fasulyesi genotiplerinin bitki tane verimi yönünden stabilitelerini parametrik ve parametrik olmayan yöntemler kullanarak değerlendirmek amacıyla yürütülmüştür.

\section{Materyal ve Metot}

Çalışmada materyal olarak Türkiye de geliştirilmiş olan 11 sebze tipi sakız fasulyesi hattı (SF1-SF11) ile Pakistan orijinli Samen çeşidi kullanılmıştır. Araştırma 2017 yılında Çanakkale, Balıkesir-Bandırma, Balıkesir-Burhaniye, İzmirBayındır lokasyonlarında tesadüf blokları deneme desenine göre üç tekerrürlü olarak yürütülmüştür. Denemelerin ekimleri gerçekleştirilmeden önce her lokasyondan 0-30 cm derinlikte toprak örneği alınmıştır. Toprak örnekleri Çanakkale Onsekiz Mart Üniversitesi (ÇOMÜ) Merkez loboratuarından analiz edilmiştir. Analiz sonuçlarına göre Bandırma ve Bayındır lokasyonun tınlı, Burhaniye'nin kumlutınlı, Çanakkale'nin killi-tınlı toprak yapısında olduğu tespit edilmiştir. Deneme alanlarının organik madde içeriği Bandırma lokasyonunda $\% 2.85$, Burhaniye'de, \%1.00, Bayındır'da, \%1.11, Çanakkale'de, ise \%1.34'tür. Deneme alanı topraklarının $\mathrm{pH}^{\prime} \mathrm{sı}$ ise 7 (Bayındır) ile 8.15 (Çanakkale) arasında değişmiştir. Ekim, Çanakkale ve Bandırma lokasyonunda Mayıs ayının ilk haftasında, Burhaniye ve Bayındır lokasyonunda Nisan ayının son haftasında gerçekleştirilmiştir. Parseller $2 \mathrm{~m}$ uzunluğunda, $40 \mathrm{~cm}$ sıra arası 
mesafede dört sıradan oluşturulmuştur. Ekim el markörü ile açılan sıralara $10 \mathrm{~cm}$ sıra üzeri mesafe olacak şekilde ocak usulü (her ocak üç tohum olacak şekilde) ile yapılmıştır. Çıkış gerçekleştiği zaman seyreltme yapılarak her ocaktaki bitki sayısı teke düşürülmüştür. Denemelerde ekimle birlikte 3 $\mathrm{kg} / \mathrm{da}$ saf azot ve $6 \mathrm{~kg} / \mathrm{da}$ fosfor taban gübresi olarak verilmiştir. Çanakkale, Bandırma, Burhaniye1 ve Bayındır lokasyonunda denemeler damla sulama ile $4 \mathrm{kez}$ (her seferde yaklaşık $100 \mathrm{~mm} \mathrm{su}$ ) sulanmış, çıkıştan iki hafta sonra bir kez çapalanmıştır. Burhaniye lokasyonunda 5 gün (buharlaşmanın tamamı) ve 10 gün sulama aralığında (buharlaşmanın tamamı) sulama yapılan iki deneme daha kurulmuştur. Bu iki deneme de Burhaniye-2 ve Burhaniye-3 çevresi olarak değerlendirilmiştir. Bu iki deneme ile birlikte araştırma toplam altı çevrede (Çanakkale, Bandırma, Bayındır, Burhaniye-1, Burhaniye-2 ve Burhaniye-3) yürütülmüştür. Yabancı ot mücadelesi ekim öncesinde (Benfluralin aktif maddeli herbisit) ve çıkış sonrasında (bentazone aktif maddeli herbisit) fasulye için ruhsatlandırılmış olan herbisitler kullanılarak yapılmıştır. Her lokasyonda hasat işlemleri el, harman işlemleri ise parsel harman makinası/biçerdöver ile yapılmıştır. Denemelerde her parselden etiketlenerek ayrı ayrı hasat ve harman yapılan 10 adet bitkiden elde edilen tane verimlerinin ortalaması alınarak $\mathrm{g}$ bitki $^{-1}$ belirlenmiştir (Vir ve Singh, 2015).

Her lokasyonda genotiplerde incelenen bitkide tane verimi değerlerine öncelikle SAS JMP programında birleştirilmiş varyans analizi yapılmıştır. Lokasyonlara ait elde edilen ortalamaların daha sonra $\mathrm{R}$ tabanlı çalışan online STABILITYSOFT programı ile stabilite analizleri yapılmıştır (Pour-Aboughadareh ve ark., 2019). STABILITYSOFT programı ile 16 adet parametrik ve parametrik olmayan $\left(\theta_{\mathrm{i}}=\right.$ ortalama varyans komponenti; $\theta_{(\mathrm{i})}=$ Genotip çevre varyans komponenti; $\mathbf{W}^{2}{ }^{2}=$ ekovalans stabilite indeksi; $b_{i}=$ regresyon katsayısı; $\mathrm{Sd}_{\mathrm{i}}{ }^{2}=$ regresyondan sapma kareler ortalaması; $\sigma_{i}^{2}=$ stabilite varyansı; $\mathrm{CV}_{\mathrm{i}}=$ çevresel değişim katsayısı; $S^{(1)}$ ve $S^{(2)}=$ Nassar ve Huhn'in parametrik olmayan istatistikleri; $\mathrm{S}^{(3)}$ and $S^{(6)}=$ Huhn'in parametrik olmayan istatistikleri; $\mathrm{NP}^{(1-4)}=$ Thennarasu'nun parametrik olmayan istatistikleri; KR = Kang'ın sıra toplamı) stabilite parametresi belirlenmiştir. Stabilite parametreleri arasındaki ilişkiler ise korelasyon analizi (PourAboughadareh ve ark., 2019) ve biplot analizi (Yan, 2014) ile değerlendirilmiştir.

\section{Bulgular ve Tartışma}

Bitki tane verimine ait birleşik varyans analizi sonuçları Çizelge 1'de verilmiştir. Çizelge de görüldüğü gibi varyasyon kaynaklarından çevre, genotip ve genotip $x$ çevre interaksiyonu $P<0.001$ ihtimal düzeyinde istatistiksel olarak önemli bulunmuştur. Varyasyon kaynakları içerisinde en yüksek açıklama oranına çevre (\%59.2) sahip olurken, ikinci en yüksek açıklama oranına \%27.9 ile genotip, en düşük açıklama oranına ise \%12.6 ile genotip $x$ çevre interaksiyonu sahip olmuştur (Çizelge 1).

Çizelge 1. Bitki tane verimine ait birleştirilmiş varyans analiz sonuçları

\begin{tabular}{lccccc}
\hline Varyasyon Kaynakları & SD & Kareler Ortalaması & F Değeri & Pr $>$ F & Varyans (\%) \\
\hline Çevre (Ç) & 5 & 469.43 & 509.6 & $<.0001$ & 59.2 \\
Blok(Ç) & 12 & 0.86 & 0.9 & 0.51 & 27.9 \\
Genotip (G) & 11 & 100.39 & 109.0 & $<.0001$ & 12.6 \\
Ç*G & 55 & 9.13 & 9.9 & $<.0001$ & \\
Hata & 132 & 0.92 & & & \\
\hline
\end{tabular}

*Belirtme katsayısı $\left(R^{2}\right)=0.97$, Değişim katsayısı $(\% C V)=9.16$, Genel Ortalama=10.47 g

Genotiplerin çevreler üzerinden bitkide tane verimi ortalamaları, duncan ortalama grupları ile stabilite parametreleri Çizelge 2'de, sıra değerleri Çizelge 3'te verilmiştir. Genotiplerin bitkide tane verim değerleri- $7.55 \mathrm{~g}$ ile $15.44 \mathrm{~g}$ arasında değişim göstermiştir. En yüksek bitkide tane verimi SF10 genotipinde $15.44 \mathrm{~g}$ (a grubu) belirlenmişken, bu genotipi $13.60 \mathrm{~g}$ (b grubu) ile SF11, $11.41 \mathrm{~g}$ (c grubu) ile SF4 takip etmiştir. En düşük bitkide tane verimine ise SF1 genotipinde $7.55 \mathrm{~g}$ (g grubu) olarak belirlenmiştir. İkinci sıradaki en düşük bitki tane verimi ise $8.06 \mathrm{~g}$ ( $\mathrm{fg}$ grubu) ile SF6 ve SF7 genotiplerinde belirlenmiştir. Bu çalışmada tespit edilen bitki tane verimleri Ashwini ve ark., (2019) tarafından sebze tipi sakız fasulyesi genotiplerinde belirlenen $6.83 \mathrm{~g}-16.67 \mathrm{~g}$ değerleri ile benzerlik göstermiştir.

Farklı çevrelerde değişik bitkiler ile yürütülen denemelerde incelenen kantitatif özelliğin yüksek olması isteniyor ise, hem parametrik hem de parametrik olmayan stabilite yöntemlerinin ( $b_{i}$ ve $R^{2}{ }_{i}$ gibi 1.0'a göre kontrol 
edilen katsayı niteliğindeki terimler hariç) çoğunluğunda düşük değerlere sahip olan genotipler stabil olmaktadır (Becker ve Leon, 1988; Akçura ve Kaya, 2008; Akçura ve ark., 2006; Zaluski ve ark., 2020). Ancak, stabilite parametrelerinde düşük değerlere sahip olan genotiplerin incelenen özellik yada özellikler yönünden genel ortalamadan daha yüksek değerlere sahip olması gerekir (Akçura ve ark., 2006).

Parametrik stabilite analizlerinden $W_{i}{ }^{2}$ ve $\sigma^{2}{ }_{i}$ ye göre ortalamadan yüksek tane verimine sahip olan SF2 genotipi en stabil genotiptir (Çizelge 2 ve Çizelge 3). Samen çeşidi ile SF4 ve SF2 genotipi ise $s^{2} d_{i}$ ve $C V i$ parametreleri yönünden stabil olmuşlardır. Regresyon katsayısı $\left(b_{i}\right)$ parametrik stabilite analiz yöntemleri arasında en yaygın kullanılanıdır. Regresyon katsayısının istatistik değerlendirilmesi 1.0'a göre $\mathrm{t}$ testi kullanılarak karşılaştırma yapılır. Buna göre SF6, SF8, SF9 SF10 ve SF11 genotiplerinin regresyon katsayısı istatistiksel olarak 1.0'dan farklıdır. Regresyon katsayısına göre istatistiksel olarak 1.0'dan farklı olmayan katsayı değeri ile bitki tane verimi genel ortalamadan yüksek olan Samen çeşidi SF2 ve SF4 genotipleri stabildir. $\theta_{(i)}$ ye göre Samen ve SF2, $\theta_{i}$ ye göre ise SF11 ve SF10 genotipleri stabildir.

Çizelge 2. Yemeklik sakız fasulyesi genotiplerinin bitki tane verimine ait stabiliteleri

Genotipler

\begin{tabular}{|c|c|c|c|c|c|c|c|c|c|c|c|c|}
\hline Yöntemler & SF1 & SF2 & SF3 & SF4 & SF5 & SF6 & SF7 & SF8 & SF9 & SF10 & SF11 & Samen \\
\hline $\mathrm{Y}(\mathrm{g})$ & $7.55 \mathrm{~g}$ & $11.05 c$ & $10.08 \mathrm{de}$ & $11.41 \mathrm{c}$ & $9.84 \mathrm{e}$ & $8.06 \mathrm{fg}$ & $8.06 \mathrm{fg}$ & $8.47 f$ & $10.75 \mathrm{~cd}$ & $15.44 a$ & $13.60 \mathrm{~b}$ & $11.41 \mathrm{c}$ \\
\hline$S^{(1)}$ & 1.73 & 1.20 & 1.93 & 2.20 & 0.87 & 1.67 & 0.93 & 4.13 & 3.20 & 0.33 & 4.60 & 1.60 \\
\hline$S^{(2)}$ & 2.27 & 1.07 & 2.57 & 3.37 & 0.70 & 1.90 & 0.67 & 12.27 & 7.07 & 0.17 & 18.30 & 1.87 \\
\hline$S^{(3)}$ & 4.86 & 0.64 & 1.79 & 2.06 & 0.64 & 3.80 & 1.25 & 14.15 & 4.24 & 0.07 & 10.76 & 1.12 \\
\hline$S^{(6)}$ & 3.43 & 0.56 & 1.02 & 1.10 & 0.73 & 2.80 & 1.50 & 3.85 & 1.68 & 0.14 & 2.59 & 0.72 \\
\hline$N P^{(1)}$ & 1.17 & 1.17 & 1.83 & 2.83 & 2.00 & 4.50 & 1.50 & 4.50 & 3.50 & 3.17 & 5.17 & 2.67 \\
\hline$N P^{(2)}$ & 2.33 & 0.13 & 0.17 & 0.43 & 0.23 & 1.60 & 1.53 & 1.00 & 0.27 & 0.74 & 0.39 & 0.16 \\
\hline$N P^{(3)}$ & 0.76 & 0.16 & 0.27 & 0.42 & 0.41 & 1.82 & 0.66 & 1.09 & 0.45 & 0.36 & 0.61 & 0.35 \\
\hline$N P^{(4)}$ & 0.74 & 0.14 & 0.27 & 0.27 & 0.16 & 0.67 & 0.35 & 0.95 & 0.38 & 0.03 & 0.54 & 0.19 \\
\hline$W_{i}{ }^{2}$ & 0.75 & 0.72 & 2.61 & 9.19 & 2.64 & 13.47 & 2.50 & 21.33 & 10.54 & 24.63 & 76.81 & 2.10 \\
\hline$\sigma_{i}^{2}$ & -0.12 & -0.13 & 0.32 & 1.90 & 0.33 & 2.93 & 0.29 & 4.81 & 2.23 & 5.61 & 18.13 & 0.20 \\
\hline$s^{2} d_{i}$ & 0.10 & 0.10 & 0.07 & 0.40 & 0.11 & 0.26 & 0.07 & 0.04 & 0.07 & 0.99 & 2.31 & 0.04 \\
\hline$b_{i}$ & 0.97 & 0.97 & 0.82 & 1.31 & 0.83 & 0.58 & 0.83 & 0.43 & 0.61 & 1.52 & 1.96 & 1.17 \\
\hline $\mathrm{CVi}$ & 46.66 & 31.97 & 29.53 & 42.09 & 30.77 & 26.90 & 37.17 & 18.62 & 20.57 & 36.39 & 53.81 & 36.99 \\
\hline$\theta_{(\mathrm{i})}$ & 3.33 & 3.33 & 3.29 & 3.15 & 3.29 & 3.05 & 3.29 & 2.88 & 3.12 & 2.81 & 1.67 & 3.30 \\
\hline$\theta_{\mathrm{i}}$ & 1.75 & 1.75 & 1.96 & 2.68 & 1.96 & 3.14 & 1.95 & 4.00 & 2.82 & 4.36 & 10.05 & 1.90 \\
\hline$K \mathrm{R}$ & 14.00 & 6.00 & 12.00 & 11.00 & 14.00 & 20.00 & 14.00 & 19.00 & 14.00 & 12.00 & 14.00 & 6.00 \\
\hline
\end{tabular}

$\theta_{i}=$ ortalama varyans komponenti; $\theta_{(i)}=$ Genotip çevre varyans komponenti; $W_{i}{ }^{2}=$ ekovalans stabilite indeksi; $b_{i}=$ regresyon katsayısı; $\mathrm{Sdi}_{i}{ }^{2}=$ regresyondan sapma kareler ortalaması; $\sigma_{i}{ }^{2}=$ stabilite varyansı; $\mathrm{CV}_{i}=$ çevresel değişim katsayısı; $S^{(1)}$ ve $S^{(2)}=$ Nassar ve Huhn'in parametrik olmayan istatistikleri; $S^{(3)}$ and $S^{(6)}=$ Huhn'in parametrik olmayan istatistikleri; $\mathrm{NP}^{(1-4)}=$ Thennarasu'nun parametrik olmayan istatistikleri; $K R=$ Kang'ın sıra toplamı; $\mathrm{Y}=$ bitki tane verimi $(\mathrm{g})$ 
Çizelge 3. Genotiplerin stabilite yöntemlerinin sıra değerleri

\begin{tabular}{|c|c|c|c|c|c|c|c|c|c|c|c|c|}
\hline \multirow{2}{*}{ Yöntemler } & \multicolumn{12}{|c|}{ Genotipler } \\
\hline & SF1 & SF2 & SF3 & SF4 & SF5 & SF6 & SF7 & SF8 & SF9 & SF10 & SF11 & Samen \\
\hline$Y$ & 12 & 5 & 7 & 4 & 8 & 11 & 10 & 9 & 6 & 1 & 2 & 3 \\
\hline$S^{(1)}$ & 7 & 4 & 8 & 9 & 2 & 6 & 3 & 11 & 10 & 1 & 12 & 5 \\
\hline$S^{(2)}$ & 7 & 4 & 8 & 9 & 3 & 6 & 2 & 11 & 10 & 1 & 12 & 5 \\
\hline$S^{(3)}$ & 10 & 3 & 6 & 7 & 2 & 8 & 5 & 12 & 9 & 1 & 11 & 4 \\
\hline$S^{(6)}$ & 11 & 2 & 5 & 6 & 4 & 10 & 7 & 12 & 8 & 1 & 9 & 3 \\
\hline$N P^{(1)}$ & 1 & 1 & 4 & 7 & 5 & 10 & 3 & 10 & 9 & 8 & 12 & 6 \\
\hline$N P^{(2)}$ & 12 & 1 & 3 & 7 & 4 & 11 & 10 & 9 & 5 & 8 & 6 & 2 \\
\hline$N P^{(3)}$ & 10 & 1 & 2 & 6 & 5 & 12 & 9 & 11 & 7 & 4 & 8 & 3 \\
\hline$N P^{(4)}$ & 11 & 2 & 6 & 5 & 3 & 10 & 7 & 12 & 8 & 1 & 9 & 4 \\
\hline$W_{i}^{2}$ & 2 & 1 & 5 & 7 & 6 & 9 & 4 & 10 & 8 & 11 & 12 & 3 \\
\hline$\sigma^{2}{ }_{i}$ & 2 & 1 & 5 & 7 & 6 & 9 & 4 & 10 & 8 & 11 & 12 & 3 \\
\hline $\mathrm{s}^{2} \mathrm{~d}_{\mathrm{i}}$ & 7 & 6 & 4 & 10 & 8 & 9 & 5 & 1 & 3 & 11 & 12 & 2 \\
\hline $\mathrm{CVi}$ & 11 & 6 & 4 & 10 & 5 & 3 & 9 & 1 & 2 & 7 & 12 & 8 \\
\hline$b_{i}$ & 6 & 5 & 9 & 3 & 7 & 11 & 8 & 12 & 10 & 2 & 1 & 4 \\
\hline$K \mathrm{R}$ & 6 & 1 & 4 & 3 & 6 & 12 & 6 & 11 & 6 & 4 & 6 & 1 \\
\hline$\theta_{(\mathrm{i})}$ & 2 & 1 & 5 & 7 & 6 & 9 & 4 & 10 & 8 & 11 & 12 & 3 \\
\hline$\theta_{i}$ & 11 & 12 & 8 & 6 & 7 & 4 & 9 & 3 & 5 & 2 & 1 & 10 \\
\hline Sıra Toplamı & 116 & 51 & 86 & 109 & 79 & 139 & 95 & 146 & 116 & 84 & 147 & 66 \\
\hline & 9.7 & 4.3 & 7.2 & 9.1 & 6.6 & 11.6 & 7.9 & 12.2 & 9.7 & 7.0 & 12.3 & 5.5 \\
\hline Ortalama sıra & & & & & & & & & & & & \\
\hline $\begin{array}{l}\text { Sira standart } \\
\text { Sap. }\end{array}$ & 3.8 & 3.0 & 2.0 & 2.1 & 1.8 & 2.7 & 2.5 & 3.8 & 2.4 & 4.2 & 3.9 & 2.3 \\
\hline
\end{tabular}

Parametrik olmayan stabilite yöntemlerinden $S^{(1)}, S^{(2)}, S^{(3)}, S^{(6)}$ ve $N P^{(4)}$ e göre en stabil olan genotip SF10 dur. NP(1) $N P^{(2)}, N P^{(3)}$ ve KR parametrik olmayan stabilite yöntemlerine göre ise en stabil olan SF2 genotipidir. Sıra toplamı ve sıra ortalaması yönünden Samen çeşidi ile SF2 genotipi en stabil olan genotiplerdir.

Farklı çevrelerde yürütülen denemelerde incelenen bitki tane verimi yönünden stabil genotipleri belirlemek amacıyla kullanılan yöntemler ile bitki tane verimi arasındaki ilişkileri değerlendirmek amacıyla oluşturulan heatmap Şekil 1'de verilmiştir. Renk değişimlerine göre parametreler arasındaki ilişkilerin yönü ve derecesinin değiştiği bu yöntemde kırmızı renk korelasyon katsayısının 1.0 olduğunu, yeşil renk ise korelasyon katsayısının -1.0 olduğunu ifade etmektedir. Buna göre, tane verimi $(Y)$ ile parametrik yöntemlerden bi ve $s^{2} d_{i}$ arasında olumlu ve önemli ilişki tespit edilmiştir. Temel olarak genotiplerin farklı çevrelerdeki verim sıralaması kullanılarak en yüksek değere sahip olan genotipe 1 verilerek hesaplan parametrik olmayan yöntemler ile tane verimi arasındaki en yüksek ilişkiler $S^{(6)}, N P^{(2)}, N P^{(3)}, N P^{(4)}$ ve $K R$ arasında tespit edilmiştir. 


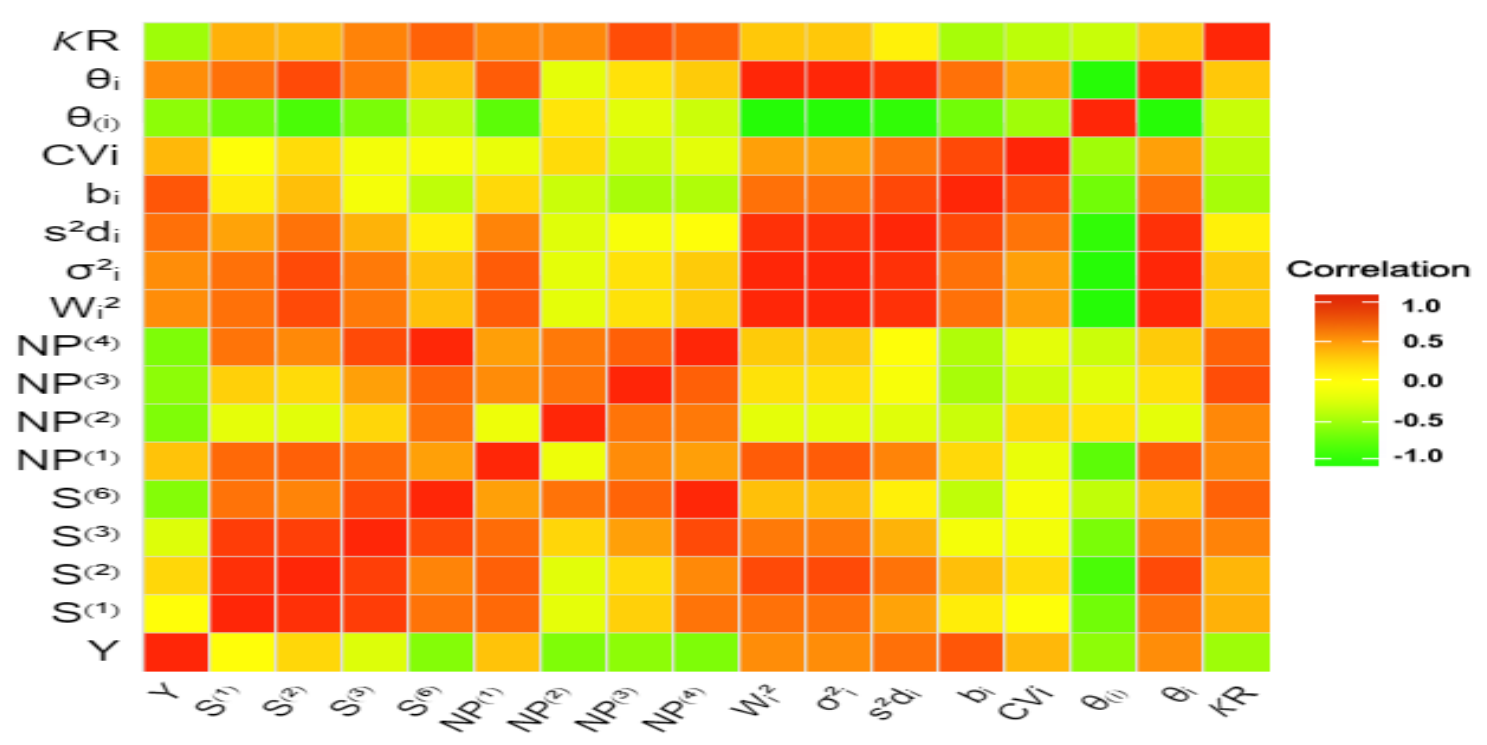

Şekil 1. Stabilite yöntemleri ile bitki tane verimi (Y) arasındaki ilişkiler

Heatmap verileri kullanılarak stabilite parametrelerinin gruplandırılması amacıyla oluşturulan biplot Şekil 2'de verilmiştir. Biplot üzerinde yöntemler beş grup oluşturmuştur. Beklenildiği gibi tane verimi ile olumlu ve önemli ilişkiye sahip olan bi hemen hemen aynı vektör uzunluğuna sahip olarak aynı grupta yer almıştır. $\mathrm{Bu}$ grupta incelenen parametrelerden en düşük vektör uzunluğundan birisine sahip olan ve tane verimi ile olumlu ancak önemsiz ilişkiye sahip olan CVi de yer almıştır. Birinci gruba en yakın olan ve bu gruptaki parametreler ile olumlu korelasyona sahip olan yöntemler $\left(\sigma_{i}^{2}, s^{2} d_{i}, \theta_{i}\right.$ ve $\left.W_{i}\right)$ ikinci parametre grubunu oluşturmuştur. Tane verimi ile olumsuz ve önemli korelasyona sahip olan $S^{(6)}$, $N P^{(2)}, N P^{(3)}, N P^{(4)}$ ve KR yöntemleri ise IV. Grubu oluşturmuştur.

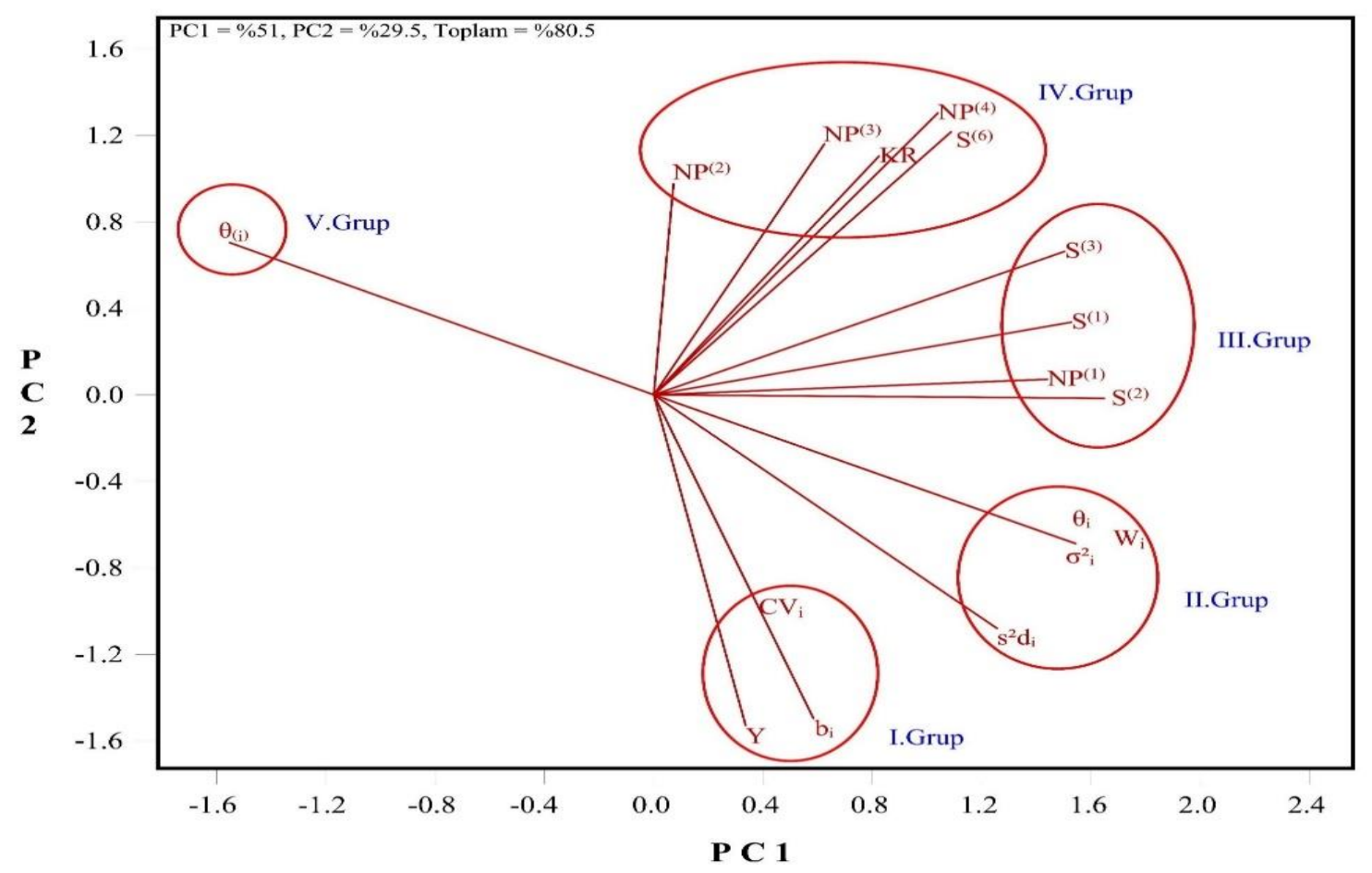

Şekil 2. Stabilite yöntemlerinin gruplandırılması 


\section{Sonuç}

Sonuç olarak, (i) farklı sebze tipi sakız fasulyesi genotiplerin stabitelerini belirlemek amacıyla yürütülen bu araştırmada Samen çeşidi ile SF10 ve SF2 genotiplerinin kullanılan yöntemlerin çoğunluğuna göre en stabil olduğu, (ii) yöntemler arasında birinci, ikinci grup ve dördüncü grupta yer alan yöntemlerin sebze tipi sakız fasulyesinde tane verimi için stabil genotiplerin belirlemesinde etkin bir şekilde kullanılabileceği tespit edilmiştir.

\section{Kaynaklar}

Akcura, M., Kaya, Y., Taner, S., Ayranci, R. 2006. Parametric stability analyses for grain yield of durum wheat. Plant Soil and Environment, 52 (6), 254.

Akcura, M., Kaya, Y. 2008. Non-parametric stability methods for interpreting genotype by environment interaction of bread wheat genotypes (Triticum aestivum L.). Genetics and Molecular Biology, 31(4), 906-913.

Becker, H. C., Leon, J. 1988. Stability analysis in plant breeding. Plant Breeding 101: 1-23.

Eberhart, S. A. T., Russell, W. A. 1966. Stability parameters for comparing varieties. Crop Science 6: 36-40.

Finlay, K. W., Wilkinson, G. N. 1963. Adaptation in a plant breeding programme. Australian Journal of Agricultural Research, 14: 742754.

Fox, P., Skovmand, B., Thompson, B., Braun, H. I., Cormier, R. 1990. Yield and adaptation of hexaploid spring triticale. Euphytica, 47: 5764.

Francis, T. R., Kannenberg, L. W. 1978. Yield stability studies in short-season maize: I. A descriptive method for grouping genotypes. Canadian Journal of Plant Science, 58: 10291034.

Girish, M. H., Gasti, V. D., Mastiholi, A. B., Thammaiah, N., Shantappa, T., Mulge, R., Kerutagi, M. G. 2012. Correlation and path analysis for growth, pod yield, seed yield and quality characters in cluster bean (Cyamopsis tetragonoloba Taub.). Karnataka Journal of Agricultural Sciences, 25 (4), 498-502.

Hocaoğlu, O., Akan, K., Akçura, M. 2020. Evaluating leaf rust reactions of pure bread wheat landrace lines using non-parametric statistics. Phytoparasitica, 48: 261-271.

Huhn, M. 1990. Non-parametric measures of phenotypic stability. Part 1: Theory. Euphytica, 47: 189-1990.

Kang, M. S. 1988. A rank-sum method for selecting high-yielding, stable corn genotypes. Cereal Research Communication, 16: 113-115.
Nassar, R., Huhn, M. 1987. Studies on estimation of phenotypic stability: tests of significance for non-parametric measures of phenotypic stability. Biometrics, 43: 45-53.

Plaisted, R. I., Peterson, L. C. 1959. A technique for evaluating the ability of selection to yield consistently in different locations or seasons. American Potato Journal, 36: 381385.

Plaisted, R. L. 1960. A shorter method for evaluating the ability of selections to yield consistently over locations. American Potato Journal, 37: 166-172.

Pour-Aboughadareh, A., Yousefian, M., Moradkhani, H., Poczai, P., Siddique K. H. M. 2019. STABILITYSOFT: A new online program to calculate parametric and non-parametric stability statistics for crop traits. Applications in Plant Sciences, 7(1): e1211. doi:10.1002/aps3.1211.

Shukla, G. K. 1972. Some statistical aspects of partitioning genotype-environmental components of variability. Heredity, 29: 237-245.

Sozen, O., Karadavut, U., Akcura, M. 2017. Determination of the some yield componenets of dry bean (Pahseolus vulgaris L.) genotypes in different environments. International Journal of Agriculture and Environmental Research, 3 (5): 3755-3769.

Sozen, O., Karadavut, U., Ozcelik, H., Bozoglu, H., Akcura, M. 2018. Genotype x Environment interaction of some dry bean (Phaseolus vulgaris L.) genotypes. Legume Research, (41) 2: 189-195.

Sozen, O., Karadavut, U. 2018. Determination of Genotype $\mathrm{x}$ Environment Interactions of Some Chickpea (Cicer arietinum L.) Genotypes by Using Diferent Stability Methods. Tarım Bilimleri Dergisi, 24: 431438.

Sozen, O., Karadavut, U. 2019. Statistical Analysis Of Some Characters Affecting Yield In Chickpea Varieties Which Can Be Breeded In Arid Climate Conditions. The Journal of Global Innovations in Agricultural and Social Sciences, 7 (4): 145-149.

Thennarasu, K. 1995. On certain non-parametric procedures for studying genotypeenvironment interactions and yield stability. PhD thesis, PJ School, IARI, New Delhi, India.

Vir, O., Singh, A. K. 2015. Variability and correlation analysis in the germplasm of cluster bean [Cyamopsis tetragonoloba (L.) Taub.] in hyper hot arid climate of Western India. 
Legume Research-An International Journal, 38 (1), 37-42.

Wricke, G. 1962. Übereine Methode zur Erfassung der ökologischen Streubreite in Feldversuchen. Zeitschrift für Pflanzenzüchtung, 47: 92-96.

Yan, W. 2014. Crop Variety Trials: Data Management and Analysis John Wiley and Sons, 349.
Załuski, D., Tworkowski, J., Krzyżaniak, M., Stolarski, M. J., Kwiatkowski, J. 2020. The Characterization of 10 Spring Camelina Genotypes Grown in Environmental Conditions in North-Eastern Poland. Agronomy, 10 (1), 64, 1-13. 